\title{
Ramón J. Cárcano: ejercicio de la historiografía, liberalismo y diplomacia. Una aproximación
}

\section{Ramón J. Cárcano: exercise of historiography, liberalism and diplomacy. An approximation}

\author{
Eduardo A. Escudero \\ Universidad Nacional de Córdoba y \\ Universidad Nacional de Río Cuarto. Argentina. \\ escuderoea@yahoo.com.ar
}

\section{Resumen}

Este artículo se acerca a una figura, aunque de algún modo principal, un tanto descuidada por la historia de la historiografía en la Argentina y en Latinoamérica: la del cordobés Ramón J. Cárcano (1860-1946). Se está en presencia de un historiador liberal que suelda su intervención intelectual y política con una tradición historiográfica fundada en Buenos Aires, mixturando a su vez esa práctica, por cierto constante y sistemática, en los tiempos e instancias de un derrotero clásico, propio de un miembro destacado de la elite política del reformismo liberal, que ubica a la historia en la médula de su disputa por el poder.

El examen propuesto documenta e interpreta el esfuerzo de síntesis historiográfica resuelto por Cárcano, concreción que proyecta el territorio historiográfico al plano de la historia diplomática y política y está dispuesto a indagar, fundamentalmente, las vinculaciones entre Argentina y Brasil durante gran parte del siglo XIX. Asimismo, se busca arribar a la conceptualización que el mismo intelectual efectuara sobre la Historia y sobre su propia labor historiográfica en el contexto argentino con sus respectivos referentes, recuperando luego las voces de sus críticos para acceder al lugar ocupado por el cordobés en distintos planos del panorama intelectual e historiográfico de la Argentina y de Brasil desde finales del siglo XIX hasta casi finalizados los años treinta.

\section{Palabras clave}

Historiografía, Liberalismo, Diplomacia.

\begin{abstract}
This article approaches a figure, albeit somehow principal, rather overlooked by the history of historiography in Argentina: that of the Cordobese Ramón J. Cárcano (1860-1946). One is in front of a liberal historian that welds his intellectual and political intervention into a historiographic tradition founded in Buenos Aires, mixing simultaneously that practice, incidentally constant and systematic, in the times and moments of a classic course
\end{abstract}


characteristic of an outstanding member of the political elite of liberal reformism, placing history in the heart of the power dispute.

The analysis proposed documents and interprets the effort of historiographic synthesis resolved by Cárcano, a realisation that projects the historiographic territory onto the plane of diplomatic and poltical history, and is ready to investigate, fundamentally, the links between Argentina and Brazil during a great part of the $19^{\text {th }}$ century. Likewise, the intention is to arrive at the conceptualisation which the intellectual himself would make about History and his own historiography work in the Argentinian context with its respective references, retrieving later on his critics' voices, to access the position of the Cordobese in the different levels of the intellectual and historiographic panorama in Argentina and Brazil from the end of the $19^{\text {th }}$ century to the late thirties.

\section{Key Words}

Historiography, Liberalism, Diplomacy.

\section{Introducción}

A menudo resulta complejo conceptualizar el espacio historiográfico que se encuadra en el arco de tiempo que articula el final del siglo XIX con las primeras décadas del siglo $\mathrm{XX}$ en la Argentina. Esto obedece, fundamentalmente, al poco estabilizado perfil de los historiadores e intelectuales que lo compusieron y a la desigual cualidad de sus prácticas, tan interesantes y fundantes como solubles frente a las distintas dimensiones de la vida pública y privada, y al frágil panorama de la constitución de un saber por entonces recién en curso de institucionalización como la Historia. ${ }^{1}$ Sin embargo, existe actualmente un conjunto de estudios específicamente abocados a la problematización de la señalada experiencia intelectual, historiográfica y política, ${ }^{2}$ superando ampliamente, según se

\footnotetext{
${ }^{1}$ Véase Pablo Buchbinder, "Vínculos privados, instituciones públicas y reglas profesionales en los orígenes de la historiografía argentina", Boletín del Instituto de Historia Argentina y Americana Dr. Emilio Ravignani (Buenos Aires: No 13, 1996); Gustavo Prado, "Las condiciones de existencia de la historiografía decimonónica argentina" en Fernando Devoto y otros, Estudios de historiografía argentina II (Buenos Aires: Biblos, 1999); Alejandro Cattaruzza y Alejandro Eujanian, Políticas de la Historia. Argentina 1860-1960 (Buenos Aires: Alianza, 2003); Fernando Devoto y Nora Pagano, Historia de la historiografía argentina (Buenos Aires: Sudamericana, 2009).

${ }^{2}$ Véase Oscar Terán, Vida intelectual en el Buenos Aires fin-de-siglo (1880-1910). Derivas de la "cultura cientifica" (Buenos Aires: Fondo de Cultura Económica, 2000); Jorge Myers, "Pasados en pugna: la difícil renovación del campo histórico argentino entre 1930 y 1955", en Federico Neiburg, Federico y Mariano Ben Plotkin, Intelectuales y expertos. La constitución del conocimiento social en la Argentina (Buenos Aires: Paidós, 2004); Fernando Devoto, "Los historiadores positivistas argentinos: conjuntos e itinerarios", en Manoel Luiz Salgado Guimaraes (comp.), Estudos sobre a escrita da história (Rio de Janeiro: 7 Letras, 2006).
} 
considera, algunos trabajos de corte memorial y laudatorio que no ofrecen mayor horizonte conceptual aunque sí un valioso aporte factual. ${ }^{3}$

Además de las preguntas delimitadas por la mayoría de las indagaciones clásicas en la historia de la historiografía argentina, resultan a su vez muy significativas aquellas investigaciones que incorporan, por ejemplo y desde hace algunas décadas, otra perspectiva espacial, abriendo un territorio fértil para pensar un nuevo mapa de los estudios históricos y de la cultura histórica en perspectiva temporal: aquel que atiende a la múltiple vinculación, flujo y complejidad de un espacio intelectual y político de inercias espaciales integradas, implicando regiones, localidades, provincias y la Nación, ${ }^{4}$ y aún la escala rioplatense, ${ }^{5}$ en vistas de superar explicaciones esquemáticas y reduccionistas. En efecto, la dinámica historiográfica argentina y rioplatense, aunque definida a menudo por los espacios institucionales y la normatividad científica erigida en Buenos Aires, se nutrió de la intensa formulación de representaciones del pasado forjadas por intelectuales e historiadores provenientes de distintos puntos del país, acompañando frecuentemente los procesos de disputas identitarias y políticas y acuñando moldes interpretativos acordes a matrices de sentido de intenso apego localista o, también, guardando consonancia con un ideal de Nación que tendía a desdibujar las diferencias interiores.

Teniendo en cuenta las anteriores apreciaciones, este trabajo de índole exploratoria busca un acercamiento en torno a una figura, aunque de algún modo principal, un tanto descuidada por la historia de la historiografía en la Argentina, la del cordobés Ramón J. Cárcano (1860-1946). ${ }^{6}$ En ese sentido, el abordaje procura abrir un primer acceso a la trayectoria intelectual, institucional y escritural de uno de los actores relevantes en la dinámica historiográfica argentina desde el cambio de siglo hasta bien entrada la década de 1930. La reconstrucción de este esquema, de carácter heurístico y apoyado tanto en fuentes primarias como secundarias, se encuentra orientada por la hipótesis que afirma la presencia

\footnotetext{
${ }^{3}$ Véase Academia Nacional de la Historia, La Junta de Historia y Numismática Americana y el movimiento historiográfico en la Argentina (Buenos Aires: Academia Nacional de la Historia, 1995).

${ }^{4}$ Véase Ernesto Maeder y otros, Visiones del Pasado: estudios de historiografía de Corrientes (Corrientes: Moglia, 2004); Teresa Suárez y Sonia Tedeschi, Historiografía y sociedad. Discursos, instituciones, identidades (Santa Fe: Universidad Nacional del Litoral, 2009); Ana Clarisa Agüero, "La tensión norte", en Dossier: El pasado de las provincias. En línea: http://historiapolitica.com/dossiers/pasados-provinciales/\# [consulta 10 diciembre, 2018]; Liliana Brezzo, María Gabriela Micheletti y Eugenia Molina (comps.), Escribir la nación en las provincias (Rosario: IDEHESI-Nodo Instituto de Historia, 2013); Alejandro Eujanian, "El pasado de las provincias. Actores, prácticas e instituciones en la construcción de identidades y representaciones de los pasados provinciales en la Argentina entre la segunda mitad del XIX y la entreguerra", presentación al Dossier: El pasado de las provincias. En línea: ver enlace anterior.

${ }^{5}$ Véase Tomás Sansón Corbo, Despertar en Petrópolis. Andrés lamas y la influencia de Brasil en la Historia de los Estados de la Cuenca del Plata en el siglo XIX (Montevideo: Sicut Serpentes, 2015) y Laura Reali, Herrera. La evolución del orden. Discursos y prácticas políticas (1897-1929) (Montevideo: Banda Oriental, 2016).

${ }^{6}$ Constituye una excepción la muy interesante inserción de la figura de Cárcano en pasajes de la trama problemática propuesta en Ana Clarisa Agüero, Local, nacional: una historia cultural de Córdoba en el contacto con Buenos Aires 1880-1918 (Bernal: Universidad Nacional de Quilmes, 2017), 97; y en Paulo Cavaleri, La restauración del Virreinato. Orígenes del nacionalismo territorial argentino (Bernal: Universidad Nacional de Quilmes, 2004), 143 y ss.
} 
de un historiador liberal que suelda su intervención intelectual y política con una tradición historiográfica fundada en Buenos Aires; por lo que, en tal sentido, entre la Nación y la provincia prefirió, centralmente, a la Nación, léase: al esquema de una composición imaginaria que opta por no espesar la provinciana sino, por el contrario, a coadyuvar al bastimento de una "comunidad imaginada" revestida de "unidad". ${ }^{8}$ Sin embargo, cuenta observar de modo combinado y atento a la trayectoria del personaje, el muy gravitante papel de Cárcano en la construcción de un quizás "nuevo" centro nacional, comprendiendo que su historia puede ser nacional precisamente porque no es local, es decir, tampoco fundada en Buenos Aires, que analíticamente puede ser pensada como otra forma de lo local.

Por lo mencionado, se observa y se lee a Cárcano resolviendo una historiografía liberal de reflejo inclusive continental y mixturando sus prácticas históricas, escriturales e institucionales, por cierto constantes y sistemáticas, en los tiempos e instancias de un derrotero "clásico", propio de un miembro destacado de la elite política del reformismo liberal que ubica a la historia en la médula de sus disputas por el poder. ${ }^{9}$ Vale recordar que el intelectual y político solventó su ejercicio histórico en el marco de una etapa transicional entre viejas y nuevas formas de concebir, ejecutar y demarcar el oficio, sin la presencia de una completa estabilización del modo de operar propio de una historiografía en vía profesionalizante, aquella que idealmente buscaría a su tiempo abandonar las formas propias de la sociabilidad decimonónica.

La secuela de ese contexto y de la señalada adscripción historiográfica y política se observa, entonces, en varios de sus posicionamientos institucionales y en gran parte de las narrativas esgrimidas, las que, por ejemplo, se ocupan predominantemente de procesos y episodios nacionales no acotados a la atmósfera provinciana ni esencialmente reivindicativos de esta. Por el contrario, el esfuerzo escritural resuelto por Cárcano proyecta el territorio historiográfico al plano de la historia diplomática y política y está dispuesto a indagar, fundamentalmente, las vinculaciones entre Argentina y Brasil durante gran parte del Siglo XIX. Así, este trabajo se nutre de registros primarios que posibilitan arribar a la conceptualización que el mismo efectuara sobre la Historia y sobre su propia labor historiográfica. De igual modo, la investigación recupera las voces de sus críticos para acceder a la reconstrucción del lugar ocupado por el historiador cordobés en distintos planos del panorama intelectual e historiográfico de la Argentina y de Brasil desde finales del Siglo XX hasta casi finalizados los años treinta.

\footnotetext{
7 Véase Benedict Anderson, Comunidades imaginadas. Reflexiones sobre el origen y difusión del nacionalismo (México: Fondo de Cultura Económica, 2007 [1983]), 24-25.

${ }^{8}$ Véase Elías Palti, La nación como problema. Los historiadores y la "cuestión nacional” (Buenos Aires: Fondo de Cultura Económica, 2006 [2002]), 132.

9 En torno al denominado reformismo liberal pueden señalarse los siguientes trabajos: Eduardo Zimmerman, Los liberales reformistas. La cuestión social en la Argentina, 1890-1916 (Buenos Aires, Sudamericana/Universidad de San Andrés, 1995), y Darío Roldan, "La cuestión liberal en la Argentina en el siglo XIX. Política, sociedad, representación”, en Beatriz Bragoni y Eduardo Míguez (coords.), Un nuevo orden político. Provincias y estado nacional, 1852-1880 (Buenos Aires: Biblos, 2010).
} 
Consecuentemente, en seguida y en primer lugar se encuentra una aproximación a la trayectoria política e intelectual del historiador cordobés, recuperando algunas claves capaces de delinear su perfil historiográfico y varias de sus pertenencias institucionales, resaltando la centralidad de la tensión brasileña en la entelequia de su acicate práctico. Posteriormente se señalan los referentes que, extraídos de la autorepresentación del mismo Cárcano, posibilitan examinar la invención de su linaje, tanto en relación con los referentes internacionales como en la elección de los modelos locales. De este modo, no resulta singular, por ejemplo, la mirada detenida en el espejo de Groussac, antesala transicional al inicio demorado de la profesionalización historiográfica y figura relativa al establecimiento de la crítica en la Argentina. ${ }^{10}$ Ahí mismo, se exponen las ideas rectoras de la historiografía liberal enunciada por Cárcano y sus representaciones acerca de la tradición historiográfica argentina: su preferencial identificación con la línea estipulada por la Junta de Historia y Numismática Americana, "asociación desinteresada, grupo de hombres de distintos rumbos y distancias, que aman la patria en su suelo, en sus hombres y en sus obras, y entienden servirla pensando en ella, inspirados por un vivo sentimiento nacional". ${ }^{11}$ Como se evidencia, la palabra y la acción de Cárcano buscaron dotar y reproducir en la representación de la tradición mitrista valores de "concordancia", de cohesión ante el propósito común, de impulso de ideales "que son energía y no interés", de tolerancia, requiriendo invariablemente fidelidad a una "tradición histórica de acción progresiva".

En coincidencia con Eujanian, además es preciso señalar la necesidad de efectuar un ejercicio que permita la hermenéutica de la adquisición del "plus de distinción" por parte de quienes, desde las provincias, trazaban un camino hacia la Nación, es decir, hacia Buenos Aires, elemento decisivo que habría de "acortar la distancia relativa con las elites nacionales, radicadas generalmente en la capital del país, sede del estado nacional y, sobre todo, principal centro de acumulación de capital simbólico, financiero, cultural, social y político". ${ }^{12}$ Cárcano, como otros contemporáneos, habitó y experimentó la razón de un horizonte decididamente orientado por el alcance de un perfil cultural favorecido por la sociabilidad y membresía, el roce y la distinción expuesta ante el reconocimiento capitalino. Desde allí, la carrera ascendente, en un recorrido sin diferenciación clara entre lo público y lo privado, podía verse ya demarcada, preanunciada exitosamente, y podía estar compuesta por múltiples intervenciones políticas y posiciones de rango en la burocracia estatal del para entonces ya de diversos modos cuestionado orden conservador.

\section{Cárcano: historiografía, liberalismo y diplomacia}

La figura de Ramón J. Cárcano podría enmarcarse dentro del contorno señalado y habitado por muchos otros intelectuales y políticos sobresalientes en la construcción y reforma del Estado liberal en la Argentina, sumando particularmente su condición de

\footnotetext{
${ }^{10}$ Alejandro Eujanian, "Paul Groussac y la crítica historiográfica", en A. Cattaruzza y A. Eujanian, Políticas de la Historia, 43 y ss.

${ }^{11}$ Véase Ramón J. Cárcano, Páginas errantes (Buenos Aires: La Facultad, 1927), 70.

${ }^{12}$ Véase A. Eujanian, "El pasado de las provincias".
} 
provinciano que articuló oportunamente intervenciones y definiciones de poder entre las esferas provincial y nacional. Dicho esto, corresponde recordar su temprana enunciación liberal en una Córdoba que se resistía a los esfuerzos y la impronta modernizantes, interpretando ese tiempo en virtud de una acción que amalgamaba y se expresaba en el régimen político conservador. Nacido en 1860, ya en 1877 había comenzado a participar de la política cordobesa como Secretario de la gobernación de Antonio del Visso y como periodista en "El Interior", tribuna liberal. ${ }^{13}$ Poco tiempo después, y reintegrado en 1880 a la Universidad de Córdoba, Cárcano reinició sus estudios hasta lograr su Licenciatura en Derecho Civil y, posteriormente, en 1884, su Doctorado en Jurisprudencia. La defensa de la Tesis "De los hijos naturales, adulterinos, incestuosos y sacrílegos", sucedida el 14 de abril del señalado año y apadrinada por el gobernador Juárez Celman, ha sido considerada por la historiografía un episodio clave que permite leer la tensión entre Iglesia y Estado, y una muestra de la heterodoxia existente dentro de la alta sociedad cordobesa, su Iglesia y su Universidad:

El clima de conmoción creado en la universidad por la presentación de la tesis [...] una de las primeras expresiones de una reacción articulada, se manifestó a través de la Pastoral del Vicario Clara. [...] El impacto de la Pastoral en la trama de un conflicto que superaba los límites de la provincia, permite vislumbrar el rol asignado a la Universidad en una lucha política en la que se ponían en juego definiciones sobre aspectos fundamentales vinculados a los valores. Conflicto nada trivial, se inscribía en una ofensiva que, encabezada por la más alta jerarquía eclesiástica, era difundida a través de un diario que marcaba la línea de acción política defendiendo unos de los baluartes decisivos. ${ }^{14}$

Todavía en medio del fragor por los debates suscitados por la polémica tesis, Cárcano ocupó una banca en la Cámara de Diputados de la Nación, situación saludada por sus amigos del partido Autonomista Nacional. Así, sus primeras armas en el parlamento le otorgaron visibilidad y solvencia, una ascensión hacia el plano político nacional que le posibilitó, luego, proyecciones internacionales. Años más tarde, por circunstancias políticas que no se pueden detallar aquí, las alianzas y reacomodamientos de facción frustraron su candidatura a Presidente de la Nación, cuando hubiera sido el sucesor de Juárez Celman. Allí:

[...] vienen casi dos décadas de ostracismo político para Cárcano. Pero ese paréntesis de la política y la función pública, impuesto por las circunstancias en un período durante el cual el roquismo, acérrimo enemigo de Juárez Celman, domina la escena política nacional, no es de

\footnotetext{
${ }^{13}$ Apuntes biográficos y algunos rasgos historiográficos pueden recuperarse de varios registros laudatorios, entre los que se citan, por orden cronológico: Manuel C. Chueco, Ramón J. Cárcano. Historiador y estadista (Buenos Aires: Biblioteca Americana, 1915); Enrique de Gandía, Los estudios históricos en la Argentina. La obra histórica de Lucas Ayarragaray y Ramón J. Cárcano (Buenos Aires: El Ateneo, 1942); Ricardo Levene y Julio C. Raffo de la Reta, Homenaje a la memoria del Dr. Ramón J. Cárcano: en el 10 aniversario de su muerte (Buenos Aires: EGLJ, 1957); Efraín U. Bischoff, "Prólogo", en Ramón J Cárcano, Ramón J. Cárcano: palabra exacta y acción fecunda (Buenos Aires: Círculo de Legisladores de la Nación Argentina, 1999). Asimismo, resulta interesante la lectura de las memorias del autor en: Mis primeros ochenta años (Buenos Aires: Domingo Viau, 1943).

${ }^{14}$ Silvia Roitenburd, "Heterodoxia en la Universidad. Ramón J. Cárcano, un intelectual entre Córdoba y la nación", en Silvia Roitenburd y Juan Pablo Abratte, Historia, política y reforma educativa: aportes críticos, transformaciones culturales y prospectiva en el espacio educativo argentino (Córdoba: Universidad Nacional de Córdoba, 2015), 143-135.
} 
ostracismo intelectual. Por el contrario, puede dedicarse a la tarea de investigar y escribir con todas sus energías. ${ }^{15}$

Por ello, en 1890 el joven político inició un viaje a Europa rico en impresiones culturales e intelectuales. Estando en Francia, quiso conocer a Taine, por quien sentía una admiración fervorosa, y aunque ello no fue posible dada la agonía y, luego, la muerte del historiador, recordó con detalles su funeral:

Concurro a la Iglesia de St. Roch donde se verifican sus exequias. En el fondo de la nave, a media luz, se divisan un humilde túmulo y algunos cirios ardiendo. Un escaso número de personas, aproximadamente ochenta, hállanse sentadas en escaños. Un pastor aparece en un púlpito instalado muy bajo, y expresa brevemente estos conceptos: "Este hombre era un sabio y un trabajador, sencillo y cordial; sus obras vivirán en la memoria de los hombres como lámparas encendidas; creía en Dios y tuvo paz en la tierra". El féretro se coloca después en un humildísimo carro que espera a la puerta. Un gran cajón, pintado de negro, con aristas amarillas, una pequeña cruz al frente, dos caballos negros al tronco, ni una palma, ni una flor. Un grupo de personas dolientes, mujeres y hombres, caminan atrás del carro. Sombreros de copa y levitas negras de todas las épocas. M. Maillard que me acompaña, los individualiza: Gaston Boissier, Ernest Lavisse, Brunetiêre, Boutmi, Dumas, Sarcey, Sorel, Daudet, Zola, Hanotaux, Maupassant, Goncourt, Hubard, Goblet, Bourjois, Liard, Bourget, Reinach, Vogüé, Berthelot, Balfour de Gran Bretaña; las eminencias intelectuales de Francia, la luz astral en la soledad y silencio de la noche. ${ }^{16}$

Estas emociones se enlazan con una determinada representación de historiador y constituyen toda una declaración de la fe liberal y positivista sostenida por Cárcano y sus referentes historiográficos. En efecto, posteriormente manifestaba:

Taine y Fustel de Coulanges han desenvuelto estas, mis ideas. Bajo la influencia de sus doctrinas, pero sin encerrarme en el riguroso determinismo de aquél, ni mirar como éste en la multitud anónima la causa de los fenómenos sociales, eligiendo de cada uno los procedimientos que en mi concepto me conducirían mejor a la posesión de la verdad, he formado el método y plan de mi trabajo. ${ }^{17}$

En el mismo sentido, un crítico posterior indica que luego, con los años, si bien Cárcano no abandonaría del todo el positivismo, a semejanza de Taine "evolucionaría hacia una historia más subjetiva y de tinte romántico" para dar con ella "la fuerza individualizadora, la percepción de las físonomías, de los estados de ánimo”, etc. Sin ello, aclara el autor, Taine no habría legado su monumental galería de retratos jacobinos, ni Cárcano, entre muchos, su Juan Facundo Quiroga. Agrega, posteriormente, que lo que nunca aceptó el cordobés fue el providencialismo ni el género panegírico de tono y gusto escolar. $^{18}$

\footnotetext{
${ }^{15}$ Rosendo Fraga, Ramón J. Cárcano Diplomático. La historia como instrumento de la diplomacia (Buenos Aires: Consejo Argentino para las Relaciones Internacionales, 1999), 8.

${ }^{16}$ Ramón J. Cárcano, citado en Mariano de Vedia y Mitre, Cárcano (Buenos Aires: Kraft, 1947), 64 y ss.

${ }^{17}$ Manuscrito inédito citado por Ricardo Saenz-Hayes, Ramón J. Cárcano, En las Letras, el Gobierno y la Diplomacia (1860-1946) (Buenos Aires: Academia Argentina de Letras, 1960), 217.

${ }^{18}$ Ibid.
} 
Liberal, entre positivista y romántico, el perfil historiográfico de Cárcano se nutre de una historia con criterio de verdad, con documentación, y en un relato impersonal siempre ajeno a la exaltación patriótica que pueda derivar en un nacionalismo agresivo. De su propia letra se lee en una carta su oposición a la historia patriótica en un documento de 1933:

[...] he creído siempre un error grave, el propósito de escribir la historia de un pueblo alrededor de un hombre, aunque se llame César, Napoleón o San Martín. Su acción e influencia, por grande que sea, es siempre transitoria y limitada en relación a la vida colectiva. La historia de un pueblo necesita abarcar todo el panorama de la vida social desde sus orígenes, todos los factores y elementos de la existencia, la evolución de las ideas y las cosas. Así una enseñanza útil y grande. ¿Puede ser la obra de un hombre? En la Universidad y en la escuela pública no enseñan la historia de acuerdo con los hechos complejos y múltiples y con las ideas que los hechos engendraron en la mente de los hombres. Los textos de historia monocorde extravían, dentro de una sola senda, el espíritu de los niños de las escuelas. Ordinariamente aparecen los ejércitos, se dan las batallas, que cuentan los muertos y heridos; pero no se sabe de dónde salen esas legiones, dónde van, quién los paga, de dónde sacan los recursos, y cómo viven. La tendencia magnificar lo propio en desmedro de lo no argentino, es motivo de malquerencia internacional: muchas de las prevenciones y rozamientos con las naciones vecinas, son a causa de los textos de historia. ${ }^{19}$

Es momento de agregar otro elemento importante que signó la escritura de la Historia en Ramón J. Cárcano: las vinculaciones entre el ejercicio de la diplomacia y la historiografía, nudo que remite a un modo de concebir la práctica política y las dimensiones del proceso histórico-estatal latinoamericano, focalizando su mirada en Brasil. El 20 de setiembre de 1909 el Conde Alfonso Celso, Max Fleiuss y José Pereira Rego Filho firmaron la solicitud de la designación del cordobés como miembro del Instituto Histórico y Geográfico del Brasil: "20 "hacía mucho tiempo que la figura de Cárcano había trascendido los límites territoriales del país. La historia diplomática de los pueblos vecinos le era familiar, y un sentido de equilibrio en los juicios, una serenidad y una simpatía expresiva, hacían al fondo de sus sentimientos americanos". ${ }^{21}$ Se iniciaba, pues, una época de intensas vinculaciones e intercambios que tendrían consecuencias historiográficas y políticas: una visión de la historia proclive a neutralizar la conflictividad exterior y a observar la armonía orgánica del desarrollo interestatal entre ambos países.

\footnotetext{
${ }^{19}$ Ramón J. Cárcano, carta inédita al Dr. Nicolás Repetto, Buenos Aires, 12 de mayo de 1933, Ibid.

${ }^{20}$ Sostiene Tomás Sansón Corbo: "Los fundadores del IHGB procuraron -a modo de conjunción y síntesis entre la experiencia de las academias del ochocientos, el paradigma del IHP y los desafíos y requerimientos de su tiempo- conjugar erudición y pragmatismo en la labor historiográfica, con el propósito de obtener el monopolio interpretativo sobre el pasado y zanjar disensos. Articularon un proyecto historiográfico condicionado por la matriz iluminista, que implicó identificar los orígenes de la nación y explicar su evolución singular por la senda del 'progreso' y la 'civilización'. Tenían por objetivo crear un relato unificador, de carácter identitario, que distinguiera a Brasil en el concierto de las naciones decimonónicas y que soslayara los potenciales elementos dispersivos que obstaculizaban la concreción de tal fin", T. Sansón Corbo, Despertar en Petrópolis, 114-115.

${ }^{21}$ Enrique Martínez Paz, Cárcano: el historiador romántico (Córdoba: Biblioteca Ramón J. Cárcano, 1973 [1951]), 12.
} 
Mientras en 1910 en la Argentina se exacerbaba el nacionalismo, Ramón J. Cárcano se incorporaba al Instituto Histórico y Geográfico del Brasil expresando:

\begin{abstract}
Abiertas las puertas por la bondad, penetro a esta casa como a un templo secular, el espíritu reconcentrado en los grandes recuerdos, la frente inclinada por la magnitud de los respetos, el corazón palpitante por la intensidad del agradecimiento... Es que me hallo en el santuario de la mente nacional, y todo lo iluminan y enaltecen las glorias del Brasil [...] yo sé que la fraternidad intelectual de este Instituto, es molde de fraternidad internacional; yo sé que en el movimiento de las simpatías, todos aspiramos a borrar las fronteras de las naciones. ${ }^{22}$
\end{abstract}

Las imágenes vertidas se asemejan, y cuasi refrendan, las pronunciadas por Bartolomé en el mismo Instituto en la sesión del 1 de diciembre de 1871 cuando se agregaba a la corporación, perfilando una evidente y estratégica equivalencia. Así, el discurso de Cárcano finalizaba celebrando la concordia sellada históricamente entre Brasil y Argentina, paz que, firmada a principios del siglo XIX, iba a cumplir también un Centenario, ocasión de celebración "con la asociación jubilosa del mundo civilizado y el alto y justo orgullo de toda América". Se observa, entonces, la articulación pasado-presente y la memoria ejercitada merced al instrumento poderoso de la diplomacia. En esa dirección, veintitrés años más tarde, Cárcano fue designado Embajador argentino en Brasil (19331938). En la plenitud de esa actuación representativa, en 1937 la Academia Brasileña de Letras $^{23}$ le publica Volando sobre los siglos, trabajo que procura narrar la "experiencia común" entre Argentina y Brasil y, asimismo, le traduce al portugués algunas de sus obras historiográficas como la biografía de Facundo Quiroga y el texto De Caseros al 11 de Septiembre. Paralelamente, en este período Cárcano comienza a incorporar la Guerra de la Triple Alianza como centro de interés temático de sus trabajos históricos. ${ }^{24}$

Así, dando curso a su pensamiento político, diplomático e historiográfico, en la Academia Brasileña de Letras, Cárcano sostenía, en nombre del progreso, que habían desaparecido todos los factores que pudieran inquietar la convivencia internacional y que habían ya crecido todos los componentes que garantizaban la armonía de recíprocos intereses. Así:

Los gobiernos han modelado su estructura definitiva y vuelto inconmovible su autoridad legal, han formado la conciencia de su nacionalidad geográfica, y creado el poder suficiente para sostener la soberanía por el derecho y por la fuerza, Los pueblos han alcanzado la prosperidad progresiva del trabajo, y adquirido las virtudes tranquilas de la holgura. Las naciones se rigen

\footnotetext{
${ }^{22}$ Ramón J. Cárcano, Cuestiones y juicios (Buenos Aires: Juan A. Alsina, 1910), 89.

${ }^{23}$ Es preciso recordar que también Bartolomé Mitre había sido miembro de esa institución, Véase Carlos de Macedo Soares, "Bartolomé Mitre en el Instituto Histórico y Geográfico Brasileño y la Academia Brasileña de Letras", en Academia Nacional de la Historia, Mitre. Homenaje de la Academia Nacional de la Historia en el cincuentenario de su muerte (1906-1956) (Buenos Aires: Academia Nacional de la Historia, 1957), 57-61. Como se observa, Cárcano cristaliza una suerte de paralelismo, replicando las mismas pertenencias.

${ }^{24}$ R. Fraga, Ramón J. Cárcano Diplomático, 27. En el trabajo de Horacio Crespo (2009) se encuentra un análisis puntual de la obra de Cárcano sobre la Guerra del Paraguay. Véase Horacio Crespo, "La Guerra del Paraguay como problema historiográfico. La interpretación de Ramón J. Cárcano”, en Nuevo Mundo Mundos Nuevos. En línea: http://nuevomundo.revues.org/55581; DOI: 10.4000/nuevomundo.55581[consulta 10 diciembre, 2018].
} 
por las mismas instituciones y buscan en las contiendas pacíficas el perfeccionamiento de prácticas políticas. Todos los países de Sud-América labran su destino en paz y concordia, en el amplio seno de la misma democracia. No existe ninguna disidencia que separe al Brasil y Argentina. Ninguna cuestión pendiente, ningún interés o ambición que en el futuro las divida. Las aproximan y las unen la raza, las instituciones, el océano que baña sus costas, la misma comunicación fluvial, la misma vía férrea que busca el Uruguay, las fuentes y orientaciones diversas de la riqueza y el comercio, la conveniencia de cambiarse los diferentes productos, la misma necesidad de poblar y civilizar inmensos territorios, una vida rica en pruebas y triunfos comunes, las tradiciones de fraternidad y alianza, el horizonte iluminado de la historia. ${ }^{25}$

Cárcano hacía explícita la idea de que Brasil y Argentina habían nacido de un antagonismo, desenvuelto "en líneas paralelas, como una carrera de leones en tierras y mares desconocidos”. Pretendía ofrecer, también, una imagen capaz de legitimar el desarrollo de dos naciones en análogo curso, identificadas con la misma raza y con un mismo lenguaje de origen, a su vez gobernadas por el mismo régimen y conducidas por la misma fe. Para el historiador, Brasil y Argentina:

Se excluyen pero no se destruyen, no pretenden despojarse sino descubrir y conservar, y la intransigencia con este concepto alguna vez lleva la guerra. [...] Las dos familias, que son dos pueblos hermanos, sienten la emulación de su propio engrandecimiento, empujados por el espíritu aventurero de su tiempo. Recién hoy podemos apreciar en toda su magnitud el esfuerzo y estructura férrea del conquistador, cuando recorremos con el vuelo de los cóndores, los mares y las tierras, las montañas y los bosques, que aquellos hombres exploraron con sus pies y sus brazos formidables, su coraje incoercible, con todas las pasiones y recursos del alma creadora, alcanzando la victoria más titánica de los siglos. [...] Se analizan sucesos, instituciones y hombres, pero en todo el desenvolvimiento de la vida heroica y fecunda, Iberia y Lusitania, adversarios o hermanos, no tienen nada que ocultar, disimular o condenar recíprocamente. [...] A cada instante brota el tema de la epopeya. Son hombres de la misma raza y del mismo clima. Gloria al Brasil y Argentina en todos los momentos de su historia. ${ }^{26}$

Las afirmaciones transcriptas facilitan la comprensión del concepto sostenido por Cárcano en cuanto al rol que históricamente cumplieron, cumplían y habrían de cumplir, en hermanado lazo, Brasil y Argentina, en tanto factor preciso para el desarrollo armonioso de América del Sur (Crespo, 2009). ${ }^{27}$ Es una idea política que se desenvuelve y esgrime en los años treinta en una evidente referencia a un posible contrapeso ante el avance de los Estados Unidos y los aun por entonces presentes intereses británicos en el Cono Sur. Además, exhibe una controversial posición de cara a los conflictos internacionales, fundamentalmente frente la Guerra del Paraguay, que expresa que "son las naciones más pequeñas las que en realidad han sembrado la discordia entre los dos gigantes regionales, que necesariamente deben entenderse y normar la marcha de los asuntos y las relaciones entre todos los países del área". ${ }^{28}$ Como puede distinguirse, la práctica historiográfica acude con constancia a brindar sostén a una visión de la diplomática y de la política, si bien acorde al clima internacional, no del todo novedosa: allí y mediante ello el historiador

\footnotetext{
${ }^{25}$ Ramón J. Cárcano, Volando sobre siglos (Río de Janeiro: Academia Brasileña de Letras, 1937), 87-88.

${ }^{26}$ Ibid., 15-20.

${ }^{27}$ Véase H. Crespo, "La Guerra del Paraguay".

${ }^{28}$ Ibid., 21.
} 
cordobés resolvía sin recaudos y polémicamente una ecuación significativamente liberal en un momento historiográfico local signado por los combates revisionistas. ${ }^{29}$

\section{A propósito de la disposición de instituciones, linajes y concepciones sobre la Historia}

Tempranamente, desde 1882, Cárcano evidenció inclinaciones historiográficas. Como ya se mencionó, un adelantado escrito dedicado a Juan Facundo Quiroga es nota que antecede, por ejemplo, a su tan polémica Tesis Doctoral en Jurisprudencia. En ese sentido, abriría con su Facundo un camino dedicado, entre otros variados tópicos, a la Historia, prefiriendo muchas veces intervenir en el pasado que rayaba con la Nación más que en los lindes más íntimos del pretérito provincial. Sin embargo, al joven intelectual le preocupaba en 1884 el panorama "historiográfico" de su Córdoba, al que evaluaba carente de trabajos enjundiosos capaces de superar el "laconismo" cronológico, que el crítico denominaba "de calendario”. Así, indicaba que Córdoba tenía una larga historia, un extenso catálogo de ciudadanos distinguidos y de hombres ilustres para integrar en un relato histórico y, además, remarcaba la importancia social y de la situación geográfica de la provincia, cualidades que le habían otorgado siempre un lugar predominante en los sucesos políticos de la Nación. Posteriormente añadía que Córdoba:

[Había] sentido las pruebas dolorosas, los entusiasmos febriles, los desalientos abrumadores, las angustias supremas y las satisfacciones infinitas, porque atravesaba un pueblo en su evolución orgánica. Y sin embargo, Córdoba es la Provincia argentina de que menos se ha escrito, no son conocidos ni sus hechos ni sus hombres. El libro de su historia muestra en blanco sus hojas, y los archivos voluminosos de su vida ahí están sirviendo de alimento a la polilla, sin sentir la mano investigadora del bibliófilo. El catálogo estenso [sic] de sus hombres permanece escrito con el laconismo del calendario, y apenas se conoce el nombre de algunos que influyeron en el orden nacional. ${ }^{30}$

A pesar de lo que se lee en la cita que antecede, el político e historiador que pronto se proyectaba hacia Buenos Aires y, desde allí, hacia otras latitudes latinoamericanas en acto diplomático, transitó historiográficamente con mayor frecuencia los episodios de orden nacional e internacional, fundamentando el proyecto liberal del Estado-Nación y plegando su imaginario histórico a relatos más o menos estabilizados, aquellos provenientes de los clásicos. Con predilección, Cárcano revisitaba el tiempo abierto posteriormente a Caseros y llegaba a historizar los sucesos que resultaban de modo alguno parte de un pasado reciente. Para ello, investigó en archivos públicos y en algunos privados, que consideraba eran "los más valiosos, porque son los más desconocidos y espontáneos”, y registró los diarios y publicaciones de la época, porque a su juicio "resucitan y animan el ambiente lejano, con las incidencias, el color y temperatura de sus días actuales". 31 En ese tránsito heurístico,

\footnotetext{
${ }^{29}$ Sobre este punto Horacio Crespo ha notado cómo Cárcano retomaba las ideas de Mitre y de su canciller Rufino de Elizalde del acuerdo sin condiciones con Brasil, política que guardaría a su vez consonancia con la sostenida por Andrés Lamas en Uruguay luego de la caída de Rosas. Véase Ibid.

${ }^{30}$ Ramón J. Cárcano, Perfiles contemporáneos (Córdoba: s/edit., 1885), 6-8.

31 Ramón J. Cárcano, Del sitio de Buenos Aires al campo de Cepeda (1852-1859) (Buenos Aires: Coni, 1921), IX.
} 
hacia 1895 Cárcano frecuentó a Paul Groussac, a quien luego consideraría tanto el fundador de la crítica científica en el país como su "gran maestro y amigo":

[...] fué también mi juez. Durante cuarenta años, sin que ninguna circunstancia haya interrumpido nuestra amistad, iba yo a consultarle y recibir sus lecciones sabias. Reunidos ambos en su gabinete favorito, entre pilas de libros, bajo la mirada de Taine y Renan, pintados por Bonnat. En mis trabajos históricos, que poseía en elaboración, él me señalaba los defectos y me alentaba con su benevolencia ruda y su acierto innegable. Recibía siempre su baño de luz [...]. La intensa influencia intelectual del maestro, la justicia y desinterés dc su acción, siempre creaba, aún donde parecía que destruía. Después de Taine, a él debo la disciplina de mi espíritu, y mucho de mi culto por la verdad y la belleza. ${ }^{32}$

En oportunidad de la muerte de Groussac, en julio de 1929 apareció en la revista Nosotros una intervención en la que Cárcano recuperaba un anecdotario personal que vivificaba su vínculo discipular con el crítico. De esa manera, allí también el cordobés recuperaba algunas de las premisas historiográficas del maestro, y afirmaba que no era posible escribir la historia colonial por orden cronológico, "sin incurrir en la narración menuda, casera y fatigosa de los viejos cronistas". Groussac indicaba a Cárcano que era buena técnica captar los "acontecimientos dominadores", "agrupar los hechos de mayor significación" y explicar por ellos "la evolución y desarrollo colectivos". 33 De modo alguno, por medio de Guizot y Taine, el influjo profería la visibilización del movimiento social como fenómenos, el camino hacia la superación del acontecimiento.

En ese sentido, el historiador que en 1897 había publicado en La Biblioteca, Historia, Ciencias, Letras ${ }^{34}$ que dirigía el ya mencionado y severo Groussac ${ }^{35}$ y que luego sobresaliera con sus Del sitio de Buenos Aires al campo de Cepeda (1921) y De Caseros al 11 de septiembre (1918), entre tantos otros trabajos, ${ }^{36}$ se proponía:

\footnotetext{
${ }^{32}$ Ramón J. Cárcano, "Paul Groussac", en Nosotros. Revista mensual de Letras, Arte, Historia, Filosofía y Ciencias Sociales (Buenos Aires: Año XXIII, Tomo LXV, 1929): 23-25.

${ }^{33}$ Ibid., 24.

${ }^{34}$ Ramón J. Cárcano, Estudios de historia argentina”, en La Biblioteca, Historia, Ciencias, Letras, Año II, (Buenos Aires: Tomo V, 1897).

35 Según Agüero, en esta temprana escritura Cárcano "circunscribe un objeto que, ya visitado por el Deán Funes, subrayaba el interés de una antigua realidad jurídico-territorial ensombrecida por la hegemonía atlántica; y lo hace, precisamente, en un medio capitalino [...] y luego de someter ese esfuerzo al criterio 'central' de Groussac. [...] era un cordobés el que escribía sobre una zona oscurecida del pasado nacional y que, al intentar iluminarla, devolvía algo de una antigua etapa en que Córdoba y Tucumán existían, tenían densidad y participaban de un mapa común, marcadamente ajeno a Buenos Aires", A. Clarisa Agüero, "La tensión norte", 11.

36 Entre las principales obras historiográficas de Ramón J. Cárcano se pueden mencionar: Perfiles contemporáneos (1885); Universidad de Córdoba. Algunas palabras sobre su organización (1890); Historia de los medios de comunicación y transporte en la República Argentina (1893); Cuestiones y juicios (1910); Otras cuestiones y juicios (1914); Los tratados de Lamas (1917); De Caseros al 11 de Septiembre (18511852) (1918); Del sitio de Buenos Aires al campo de Cepeda (1852-1859) (1921); Primeras luchas entre la Iglesia y el Estado en la Gobernación de Tucumán Siglo XIV (1929); Juan Facundo Quiroga. Simulación. Infidencia. Tragedia (1931); Volando sobre siglos (1937); Urquiza y Alberdi. Intimidades de una política (1939); Guerra del Paraguay. Orígenes y causas (1939); Guerra del Paraguay. Acción y reacción de la Triple Alianza (1941); Mis primeros ochenta años (1943). Es evidente que esta enumeración puede, desde ya,
} 
[...] encerrar la narración sintética de los acontecimientos políticos dominantes, externos e internos, desarrollados durante la lucha de diez años entre la Confederación Buenos Aires; determinar sus relaciones con las potencias extranjeras, especialmente con las naciones limítrofes; y señalar los resultados que se alcanzan de carácter nacional. ${ }^{37}$

Como es evidente y ha demostrado también Horacio Crespo, el aporte de Cárcano a la monumental Historia de la Nación Argentina (desde los orígenes hasta la organización definitiva en 1862) editada por la Academia Nacional de la Historia entre 1936 y 1950 estuvo abocada a la historia diplomática, con los capítulos denominados "La organización del poder después de Caseros" y "La política internacional en el Plata durante el gobierno de la Confederación. Tratados y alianzas, 1858-1859", contribuciones que delinean, sin más, toda un área especializada del saber. ${ }^{38}$

En línea con lo ya expresado, es posible admitir que la historia diplomática y política predominaba en Cárcano como modo de enfrentar la tarea de demostrar la resolución exitosa de una corriente histórica cabalmente signada por el proyecto liberal:

A la dispersión angustiosa de Arequito y la unidad sangrienta de la tiranía, sucedió la gran batalla de la liberación, que reincorporó al país la legión luminosa de los emigrados, trayendo, como fuerza vigorosa e intacta, la libertad de pensar, la independencia y entereza del sacrificio, la experiencia creadora del ostracismo. Los residentes en el país y los que regresaron de la adversidad habían formado su ideal concreto y activo, constituyendo una ambición común: la organización definitiva de la República. Existía concordancia respecto del sistema institucional a fundarse, pero aún subsistían también discordancias de intereses, antagonismos ancestrales y vivientes. La coordinación significaba la unidad nacional, y la coordinación dependía de la mejor comprensión y confianza recíproca de los hombres. ${ }^{39}$

Cárcano deducía que desde 1820 la Nación se había dividido en dos grupos, por un lado las "provincias lánguidas" y, por otro, "la metrópoli opulenta", y que ambos habían podido levantar, luego y en el horizonte, la misma bandera. Continuaba matizando que, sin embargo, aún les faltaba la "comunidad de sentimientos y la conjunción de fuerzas", y que, por ello mismo, la lucha ardiente y continua había ocupado y demorado una década. ${ }^{40} \mathrm{El}$ historiador abocado a dejar documentado y explícitamente historizado que Mitre y Urquiza no habían sido dos rivales que se excluyen por ambiciones personales, sino, a cambio, "dos exponentes de fuerzas colectivas, que luchan por constituir la propia asociación y fundar el solar definitivo", ofrecía una interpretación que remarcaba las distancias entre dos formas disímiles de arribar al mismo resultado, cuando ambas figuras simbolizaban, en realidad, "el choque de dos tendencias ancestrales dentro de del hogar común, que la presión de los

incitar a la discusión acerca de los que a raíz de distintos ángulos puedan alimentar el corpus. En este caso se ha transitado menos por el deslinde que por la convivencia de géneros diversos. Sin embargo, en el futuro la indagación tendrá que identificar secciones que, al menos, delimiten los textos más concretamente historiográficos de aquellos más definidamente memoriales-políticos.

${ }^{37}$ R. J. Cárcano, Del sitio de Buenos Aires, V.

${ }^{38}$ H. Crespo, "La Guerra del Paraguay".

${ }^{39}$ R. J. Cárcano, Del sitio de Buenos Aires, V-VI.

${ }^{40}$ Ibid., VI. 
intereses y la exaltación de sentimientos convierten en masas impulsivas, hasta que la confianza recíproca, creada por el mismo choque, las desarma y unifica en la concordia" (Cárcano, 1938: 122).

Como se lee, Cárcano creía en la concordia, en el inevitable curso de una historia de los aciertos fundamentales de un organismo social en marcha. Para ello, explicitó, de este modo, su esquema metodológico:

\begin{abstract}
Intento mostrar la extensión [del teatro de la Historia], la multitud de actores, el motor interior que les anima, las bruscas alternativas de conciliación y de violencia, las vacilaciones y contradicciones, las pasiones y errores, batallas incompletas, las victorias sin imposiciones, todo convertido en el tiempo en factores de solución nacional y definitiva, todo lo accidental subordinado a lo esencial, el triunfo del alma colectiva sobre el alma individual. He clasificado y agrupado las ideas y los hechos de modo que se aprecie ampliamente la conducta de los hombres y la significación de los acontecimientos, que por singulares que parezcan, acusan siempre intenciones y encadenamientos. ${ }^{41}$
\end{abstract}

Así, apegado a la fe en la verdad, afirmaba también que al escribir la Historia no incurría en "apología enervante y corruptora", y que, si alguna vez ensayaba "la crítica que consolida las reputaciones y labra las estatuas", posiblemente resultaría alguna vez ingrata, aunque nunca inútil. ${ }^{42}$ Como se ha dicho ya en este trabajo, el historiador abordó su propio tiempo como tiempo de la Historia, avanzando sobre territorios que de modo alguno lo implicaban generacionalmente, es decir, políticamente. Al respecto, reflexionaba Cárcano:

La proximidad relativa de los sucesos no comprometerá la imparcialidad de mi espíritu. No tengo corrientes magnéticas que me desvíen de la orientación de la verdad, ni por tradiciones de partido, ni por afinidades hereditarias, ni por intereses momentáneos, ni siquiera por el método de exposición documentado, que busca sólo contener las atracciones del hecho cierto y el juicio justo. Si no me sintiera seguro de mantener la imparcialidad no saldría del silencio. He cuidado mucho de no "filosofar". En vez de hacer historia, he preferido que la contaran sus propios actores, comprobada la exactitud de sus afirmaciones, y advertido en lo posible del móvil de sus actos. Las dependencias de los hechos que forman la construcción, no han ahogado la intervención y libertad del hombre que constatan la intención, Las ideas, los hechos, el engranaje y el movimiento, forman el conjunto de mi estudio. ${ }^{43}$

El conjunto de su operación historiográfica, más allá de las misceláneas y de los trabajos menos articulados con el núcleo de interés general, demuestra la centralidad otorgada a la visión internacional en la construcción de las naciones liberales latinoamericanas, fundamentalmente el vínculo Argentina-Brasil. Cárcano probaba que la gestión diplomática de Brasil afectaba todas las relaciones de los estados del Plata, en cuya formación había ejercido una influencia decisiva. Por ello, indicaba que se requería de su conocimiento intenso para poder "juzgar diversas situaciones decisivas o concurrentes de la política argentina". Así, también sugería que "la magnitud de la fuerza imperial, el propósito continuo, el halago o la amenaza, el aprovechamiento de circunstancias adversas

\footnotetext{
${ }^{41}$ Ibid., VII.

${ }^{42}$ Ibid.

${ }^{43}$ Ibid.
} 
del antiguo aliado o vecino, no excusa de examinar la diplomacia de las repúblicas del Plata", 44 y continuaba enseñando:

El ataque a los vencedores no cubre los errores del vencido. Sin incurrir en estériles procesos políticos, que irritan y nada fundan, es menester no explicar la conducta de nuestros gobiernos por la gravitación de causas extranjeras, sin descubrir las por qué ellas gravitaron sobre el propio organismo. La ciencia experimental de la historia significa una enseñanza, y nunca una excusa o un castigo. ${ }^{45}$

El político e historiador cordobés, portador de las ideas y estrategias de trabajo antes brevemente reseñadas, había sido incorporado en 1901 como Miembro de Número y Miembro Correspondiente por Córdoba en la Junta de Historia y Numismática Americana, mismo año en que la corporación integraba a otro referente de la misma provincia como Ignacio Garzón. ${ }^{46}$ Ambos nombres fueron los primeros en sumarse a razón de representar a Córdoba en el espacio intelectual abierto por Mitre para el encauzamiento de la labor histórica en el país. De esta manera, representaba el mismo Cárcano el derrotero de la institución:

Un grupo de hombres de espíritu selecto, se reunía periódicamente a conversar sobre temas de historia y numismática. El general Mitre presidía con frecuencia esas reuniones, que elevaba con su presencia, animaba con su palabra, y nutría con su saber. Se ocupaba el tiempo en cosas altas y tranquilas. Un libro, una medalla, temas de investigación y estudio, se analizaban sin retraimiento ni reserva, con entera independencia, el interés y encanto de la intimidad y reciproca confianza. Cada uno pensaba como quería. El General parecía cuidarse de que la gravitación de su autoridad no detuviera ninguna iniciativa, no apagara ninguna espontaneidad. Él mismo encendía las dudas y señalaba los vacíos, requería el examen y alumbraba el camino. [...] el entretenimiento salió de la instructiva disquisición, y produjo algunas monografías. Empezó el trabajo expansivo y útil, y se pensó en el trabajo regular. Surgió entonces la Junta, cuya significación la lleva en su nombre, al principio sin más carta orgánica que la propia costumbre. Primer presidente fue el General Mitre, y ha quedado nuestro presidente perpetuo. El sillón que él ocupaba no está vacío, porque lo llena su gran memoria. La Junta [...] es una fracción de su obra múltiple e inmensa, que a veces él construía al pasar, sembrando ideas y labrando instrumento de cultura. Yo no debo tocar esta figura dominante de la historia, sino para evocarla dentro de estos muros, donde la Junta tiene su sitio, como legado de su autor y expresión de un ideal. La madurez y la justicia del tiempo han destacado tanto la magnitud de su figura, que el país entero celebra el centenario [de Mitre] como una fecha de la patria, donde conmemora sacrificios y virtudes que son elementos de su historia. ${ }^{47}$

\footnotetext{
${ }^{44}$ Ibid.

${ }^{45}$ Ibid., IX.

${ }^{46}$ Sobre la figura y obra de Ignacio Garzón véase Eduardo Escudero y Agustín Rojas, "En torno a la historiografía cordobesa finisecular y el momento de las crónicas provinciales: el caso de Ignacio Garzón", en Liliana Brezzo y María Gabriela Micheletti (comps.), $V^{a}$ Jornada de discusión de avances de investigación en Historia Argentina: fuentes, problemas y método (Rosario: Instituto de Historia, Facultad de Derecho y Ciencias Sociales del Rosario, UCA Nodo Rosario - UER / IDEHESI-CONICET, 2014). Al decir de Agüero, la designación de Cárcano fue más "cosmopolita" que la de Garzón, dado que este último era en la oportunidad sólo consagrado Miembro Correspondiente por Córdoba, A. Clarisa Agüero, Local, nacional, 325-326.

${ }^{47}$ Ramón J. Cárcano, Páginas errantes (Buenos Aires: La Facultad, 1927), 90 y ss.
} 
La actividad de Ramón J. Cárcano en la Junta de Historia y Numismática Americana tuvo relieves significativos. En ese sentido, su participación como asiduo conferencista y animador institucional se coronó con su elección como Presidente durante dos períodos, entre 1919-1923 y 1931-1934. ${ }^{48}$ Como valoraba Ricardo Levene:

El doctor Cárcano no es el hombre que vive aislado en el gabinete de la meditación. [...] Su superioridad ha consistido en ser espíritu dirigente, con aptitud para construir, levantando el templo de su ideal, con fuerza para vencer la rebeldía inmotivada y anárquica. [...] Alerta en todos los cargos directivos, viendo sucederse las vicisitudes y las calmas, el escritor ha colaborado siempre junto al estadista y al descifrar los signos de los tiempos, cuando era necesario, la pluma forjaba la frase cortante arrojándola a los espacios, para descubrir una llaga social, para exaltar una virtud colectiva o para definir sagazmente un momento político. ${ }^{49}$

Acompañando el anterior laudo, Levene relató también sus impresiones al conocer y trabajar como Secretario ${ }^{50}$ junto a Cárcano y seguidamente adjudicó al evocado una importante tarea en la Junta: la de una intensa vinculación con las instituciones similares extranjeras, particularmente con la Real Academia de la Historia de Madrid y la Academia de Felipe V, las que a tiempo reconoció junto a sus miembros como académicos correspondientes; la delegación de la Junta de Buenos Aires en el Primer Congreso Internacional de Historia de América, reunido en Río de Janeiro, que obtuvo gran éxito; y la resolución del Congreso designando la ciudad de Buenos Aires para organizar el Segundo Congreso de Historia Americana. ${ }^{51}$ Lo precedentemente indicado por Levene

\footnotetext{
${ }^{48}$ Las conferencias dictadas por Ramón J. Cárcano en la Junta de Historia y Numismática Americana fueron las siguientes: "Biografía del Dr. Pablo Julio Rodríguez", el 20/10/1907; "El gobierno provisional del Paraguay. Silva Paranhos-Mariano Varela", el 15/11/1908; "Evolución política del Gral. Justo José de Urquiza", el 17/06/1917; "Relaciones diplomáticas argentino-brasileñas", el 03/08/1918; "La primera gestión diplomática de la Confederación. Conflicto entre Brasil y el Estado Oriental. 1852", el 16/05/1920; "Personalidad del Dr. Juan Francisco Seguí. Homenaje a su memoria", el 04/11/1922; "Después de Cepeda: partidos y conflictos", el 22/10/1932. Véase Noemí Girbal de Blacha y Aurora Ravina, "Listados Académicos", en Academia Nacional de la Historia, La Junta de Historia.

${ }^{49}$ Ricardo Levene, "Perfil", en Ángel Acuña y otros, Ramón J. Cárcano a través de diez escritores (Buenos Aires: Domingo Viau, 1941), 208.

${ }^{50}$ En estos términos: "El doctor Ramón J. Cárcano es un arquetipo de personalidad dotado admirablemente para hacer con sencillez grandes y duraderas obras. Conocí personalmente al doctor Ramón J. Cárcano, en el año 1917 en casa del doctor Norberto Piñero. Yo había dado una conferencia en el Museo Histórico Nacional sobre la iniciación de la vida pública Mariano Moreno, y el doctor Piñero, que no había concurrido al acto muy gentilmente a hacer la lectura en su casa ante un núcleo de En la tertulia recuerdo que estaban, entre otros, Ramón J. Cárcano, Ernesto Quesada, David Peña, Carlos Correa Luna. Terminada la lectura, el doctor Cárcano, al saludarme, alentándome con palabras generosas, me dijo que la documentación e interpretación que yo presentaba, le hacían imaginar un nuevo Mariano Moreno. En 1919, el doctor Cárcano fue designado Presidente de la Junta de Historia y Numismática Americana y yo tuve el honor de ser su Secretario. Por lo común, el trato íntimo con los grandes hombres no les favorece en el juicio que inspiran, porque la superioridad suele acusarse en una dirección o especialización en detrimento del concepto general. He tenido la fortuna de conocer y vincularme espiritualmente a argentinos eminentes de vasta cultura, y entre ellos sobresale el Dr. Cárcano. Mucho le admiraba por sus obras, pero desde el cargo de Secretario de la Junta, además de mantener encendida mi simpatía intelectual hacia el Presidente, sentí nacer en mí el afecto y el respeto hacia el hombre de maneras sencillas y distinguidas, a quien sus triunfos políticos de y la vida social activa no le apartaban de sus permanentes preocupaciones de civilizador", R. Levene, "Perfill", 208-210.

${ }^{51}$ Ibid., 209.
} 
trasciende el plano memorial. En efecto, las evidencias documentales parecen indicar claramente que el cordobés consideró pertinente y valioso profundizar los ideales propios del mandato fundacional de la Junta de Historia y Numismática Americana y expandir notablemente su dominio e influjo hacia otras latitudes.

Respecto de la tradición corporativa, Cárcano reflexionaba que existía un legado que custodiar en el solar historiográfico de Mitre, una "acción progresiva" que, sin más, se enmarcaba en un testimonio de acción colectiva de la Junta, el que se evidenciaría en resultados concretos. Asimismo, se refería a las controversias internas, intercambios que serían expresión de una "unidad moral e intelectual", que fraguaba "en consistencia y fundaba autoridad". 52 Noemí Girbal afirma que desde 1919 la Presidencia de Cárcano en la Junta de Historia y Numismática Americana ofició de "nexo entre los jóvenes y viejos académicos", aseverando que se profundizaron los perfiles del accionar corporativo inaugurados durante la presidencia de Antonio Dellepiane. ${ }^{53}$ La misma autora sitúa en el tiempo de Cárcano en la Junta a una serie de "cambios modernizadores" para proyectar un accionar sin descuidar los nexos con la tradición institucional. Se destacan, en ese sentido, la reorganización metódica de la corporación; la constitución de comisiones reglamentarias destinadas a atender sobre temas de preferente preocupación institucional; la efectivización de diversos actos conmemorativos a los miembros de la corporación ya fallecidos; el impulso al proyecto de publicación del Boletín; la incorporación de nuevos miembros de número y correspondientes en el país y en el exterior; la activación de las relaciones con la Universidad; la más frecuente participación en eventos científicos; el aumento en el número y diversidad temática de las disertaciones y reuniones en la Junta; etc. ${ }^{54}$

Según Levene, durante segunda presidencia del Ramón J. Cárcano en la Junta de Historia y Numismática Americana:

[...] se ampliaron relaciones con los Institutos Históricos de América, particularmente con los de Perú, Uruguay y Colombia y se desarrolló una acción intensa en los estudios históricos, interrumpida por su designación de Embajador en el Brasil, donde hizo de la Embajada en Río de Janeiro una casa de la cultura y de la política internacional americana. ${ }^{55}$

Sin embargo, aun en el marco de una progresiva inserción académica más amplia en la sociedad y de la ya referida instancia aperturista desenvuelta desde 1920, se remarca el apego al modelo y el faro histórico mitrista. Por ello, desde distintas intervenciones intelectuales públicas, Cárcano exhibía representaciones laudatorias respecto al fundador. Así, imaginaba públicamente que Mitre había dilatado su pensamiento en la forja de la Nación y que, movido por el sentimiento y ambición de la integridad de la República, había

\footnotetext{
52 Ramón J. Cárcano, “Discurso de Ramón J. Cárcano en la Sesión del 17/VIII/1919”, en Boletín de la Junta de Historia y Numismática (Buenos Aires: Vol. VII, 1930), 428.

${ }^{53}$ Noemí Girbal de Blacha, "La aproximación al cambio, el dinamismo interno y la transición hacia la apertura intelectual", en Academia Nacional de la Historia, La Junta de Historia, 96 y ss.

${ }^{54}$ Ibid., 96 y 98-99.

${ }^{55}$ R. Levene, "Perfill", 211.
} 
consagrado su vida a servirla en todas sus facultades. ${ }^{56}$ Sobre el padre de la historiografía argentina, Cárcano apreciaba:

El método de su propia vida observó al escribir la historia de América y de la república. Reunió prolijamente el material, clasificó las ideas, agrupó los hechos, analizó todos los factores, los depuró por la sana crítica, y reconstruyó el pasado con la conciencia y la verdad que nutría su juicio contemporáneo. La información es honda y múltiple, llena de interés en el texto, de rectitud en el criterio, de cuidado en la expresión, encerrado en cierta sequedad suave, que sólo significa dignidad y circunspección [...]. Aquí están los archivos de la historia de San Martín y Belgrano, los mapas de sus batallas, la colección más completa de libros sobre América, la colección particular más copiosa de documentos inéditos sobre la república. Encuéntranse reunidos los recuerdos más próximos y remotos, más íntimos y sugerentes de la vida intensa de Mitre; sus materiales de bajo, las anotaciones de sus libros, sus innumerables manuscritos, las huellas del desarrollo de sus estudios, la formación y ordenamiento de las ideas, los testimonios de su labor y de sus frutos. Aquí el historiador ha escrito las hazañas del gran capitán, meditado sus arengas populares y discursos parlamentarios. Diariamente hablaba al país, desde la tribuna resonante por él fundada para servirlo. ${ }^{57}$

Del mismo modo, una determinada imagen de la Junta de Historia y Numismática Americana prevalecía en las palabras de Ramón J. Cárcano. En esas consideraciones respecto del ideal corporativo, el cordobés ya consagrado y prestigiado historiográficamente en Buenos Aires valoraba cómo los fundadores de la Junta habían iniciado reimpresión auténtica y critica de aquellas obras que eran fuente originaria de la historia argentina y cómo los sucesores estaban efectivizando el trabajo de expansión intelectual y las vinculaciones internacionales que dilataban el horizonte institucional. Asimismo, un "nosotros" asentaba una jactancia: "Somos una asociación desinteresada, un grupo de hombres de distintos rumbos y distancias, reunidos periódicamente para cambiar ideas e impresiones sobre estudios y gustos predilectos". ${ }^{58}$ Cárcano aseguraba también que los miembros de la Junta de Historia y Numismática Americana amaban la patria en su suelo, en sus hombres y en sus obras, y entendían cómo servirla, precisamente pensando en ella: inspirados por un vivo sentimiento nacional. Aseguraba, asimismo, que existía una "concordancia":

[...] la cohesión del propósito común, el impulso de ideales que son una energía, pero no un interés. En nuestro trabajos y conversaciones, modestas y silenciosas, sin engreimiento ni alarde, existe una cordialidad sincera, una franqueza sin cuidados ni reservas, una intimidad respetuosa y cómoda, porque practicamos la virtud de la tolerancia, que no es indiferencia de libertad y de cultura. En medio de la fiebre devorante de esta capital, hemos creado un sitio sereno donde pueden habitar las almas, sin que las mortifiquen el desdén ni el pedantismo. ${ }^{59}$

En esa operación autorreferencial destinada a sacralizar un espacio y a fijar un linaje político para la historiografía argentina, recordaba Cárcano que siempre, más allá del tiempo, presidía las reuniones de la Junta Bartolomé Mitre, aquél hombre preclaro y

\footnotetext{
${ }^{56}$ R. J. Cárcano, Páginas errantes, 89 y ss.

${ }^{57}$ Ibid., 94-96-97.

${ }^{58}$ Ibid., 94-96-97.

${ }^{59}$ Ibid., 96-97.
} 
primero que supo inventarlas, y que si bien, su morada estaba en el cenit de la historia, su asiento en la tierra no estaba vacío, porque quedaba lleno de su gran memoria: "ella es para la Junta fuente de origen y también fuente de vida". ${ }^{60}$ Definía y defendíase, de este modo y por parte de un actor principal, un espacio a futuro representado negativamente por quienes no muy tarde reclamaban, entre otras cosas, un modo alternativo de interpretar el pasado nacional en la Argentina.

\section{A modo de cierre}

Como ya se adelantó, la figura de Ramón J. Cárcano puede enmarcarse dentro del contorno conformado por muchos otros intelectuales y políticos sobresalientes en la construcción y reforma del Estado liberal en la Argentina, sumando particularmente su condición de provinciano que habría de oportunamente articular diversas e importantes intervenciones y definiciones de poder entre las esferas provincial y nacional. Para ello, asimismo asumió un muy significativo rol historiográfico que este trabajo procuró al menos caracterizar, en vistas a su descuido por parte de la mayoría de los estudios de historia de la historiografía argentina.

En ese sentido, como resultado de la prospección y crítica de fuentes primarias y secundarias, es posible observar el modo en que Cárcano habitó la cultura histórica de ese tiempo complejo que va de entresiglos a los años treinta anudando historiografía, diplomacia y política. Allí, se lo puede distinguir actuando en medio de instituciones, escrituras y opciones historiográficas concretas: se está, en efecto, en presencia de un historiador liberal que soldó su acción intelectual y política con la tradición historiográfica fundada en Buenos Aires y que, entre la Nación y la provincia prefirió, centralmente, a la Nación. Sin embargo, como se dijo más arriba, cuenta observar de modo combinado y atento a la trayectoria del personaje, el muy gravitante papel de Cárcano en la construcción de un quizá "nuevo" centro nacional, comprendiendo que su historia puede ser nacional precisamente porque no es local, es decir, tampoco fundada en Buenos Aires, que analíticamente puede ser pensada como otra forma de lo local.

En Cárcano indudablemente arraigó una concepción ideal del sentido de la historia argentina que no formalizó un troquelado problemático al estilo de otros historiadores de origen provinciano. A contramano, como ya se dejó explicitado, adoptó y defendió cuasi fervorosamente desde la Junta de Historia y Numismática Americana el esquema de una composición imaginaria que no espesó la provinciana sino que, por el contrario, conllevó a colaborar en la continuidad de la "comunidad imaginada" de la Nación, en el marco continental.

Así, con diversas obras publicadas entre Córdoba y más abundantemente en Buenos Aires y Brasil entre 1885 y 1943, Cárcano resolvió una historiografía liberal de reflejo inclusive continental en vínculo con el despliegue de un derrotero "clásico", propio de un miembro destacado de la elite política del reformismo liberal que ubicó a la historia en la

${ }^{60}$ Ibid., 94-96-97. 
médula de sus disputas por el poder. Asimismo fue, como tantos otros, del grupo de esos historiadores de una etapa transicional entre viejas y nuevas formas de concebir, ejecutar y demarcar el oficio de la historiografía, responsables en la erección y consolidación de algunas instituciones centrales en la gestación de un "campo" destinado a la Historia, aunque todavía carentes del utillaje preciso para el tan buscado horizonte de la profesionalización disciplinar.

Asimismo, como ya se expresó en este trabajo, el esfuerzo escritural resuelto por Cárcano fue fructífero en el plano de la historia diplomática y política y se abocó a indagar, fundamentalmente, las vinculaciones entre Argentina y Brasil durante gran parte del Siglo XIX. Como ya se examinó, el cordobés sostuvo mediante estrategia historiográfica una idea política en evidente referencia a un posible contrapeso ante el avance de los Estados Unidos y los aun por entonces presentes intereses británicos en el Cono Sur: que Brasil y Argentina serían las potencias capaces de asegurar la concordia y el equilibrio regional frente también, inclusive, las naciones más pequeñas de Latinoamérica. Interesa remarcar cómo la práctica historiográfica brindaba allí sostén a una visión de la diplomática y de la política, si bien acorde al clima internacional, no del todo novedosa para la década de 1930, cuando el historiador resolvía sin recaudos y polémicamente una ecuación elocuentemente liberal en un momento historiográfico local signado por los combates revisionistas. A lo mencionado últimamente se agrega una esencial variable más de su singular percepción de la política nacional: un evidente cosmopolitismo, defendido con intensidad en franca tensión con el nacionalismo practicado como acto de defensa por gran parte de las elites que percibían y hacia suya la decadencia en la Argentina desde el Centenario. Sin embargo, vale matizar. La relación que establecida entre historiografía y política es posiblemente más reduccionista que la que permitiría defender una consideración genética del interés de Cárcano por la historia. Si bien la Historia pudo ser materia de un uso instrumental, ello no implicó en absoluto que no hubiera un interés genuino, curiosidad e inteligencia en sus operaciones historiográficas exhibidas desde distintas textualidades y variadas direcciones temáticas; y a partir de varias oportunidades de trabajos propios de la cultura histórica.

En algún pasaje primero del trabajo se retomaba a Eujanian y se indicaba la fertilidad de un ejercicio que posibilitara la hermenéutica de la adquisición del "plus de distinción" por parte de quienes, desde las provincias, trazaban un camino hacia la Nación. Se considera que el modo de operar de Cárcano permite arribar a ese ángulo analítico. Es notable cómo la Historia mediaba en la formación del miembro de la elite política, una preocupación por la cultura que ponía en marcha el flujo del capital simbólico, capital que acortaba distancias, que definía y redefinía identificaciones, que nutría espacios recién abiertos y redireccionaba los tradicionales, que derivaba en la anhelada estrechez de los vínculos y abría paso, finalmente, a la visibilidad del actor político y cultural. Cárcano, como otros contemporáneos, habitó y experimentó la razón de un horizonte decididamente orientado por el alcance de un perfil cultural favorecido por esa sociabilidad y membresía del roce y la distinción expuesta ante el reconocimiento capitalino. Por ello, y desde allí, su carrera ascendente, en un recorrido sin diferenciación clara entre lo público y lo privado, se vio a tiempo factibilizada y compuesta por múltiples intervenciones políticas y posiciones de rango exitosas en el complejo plano de la burocracia estatal. 
En esa misma dirección, resulta de valor considerar la actividad desarrollada por cordobés en la Junta de Historia y Numismática Americana desde 1901 y hasta su muerte. Siguiendo ese sentido, primero su membresía, luego su participación como constante conferencista y animador institucional y, posteriormente, su Presidencia durante dos períodos, entre 1919-1923 y 1931-1934, reponen un protagonismo digno de considerar, inclusive, por otros estudios que a futuro puedan ser más pormenorizados. Más allá de la memoria institucional, "oficial" de la Academia Nacional de la Historia, que le adjudican haber sido el nexo entre los jóvenes y viejos académicos; la profundización de los perfiles del accionar corporativo; los "cambios modernizadores" alcanzados; la reorganización metódica de la corporación; la constitución de comisiones reglamentarias destinadas a atender sobre temas de preferente preocupación institucional; etc., el análisis da cuenta también del trabajo ejecutado para prescribir los fundamentos de la tradición de Mitre. Como se expuso en páginas anteriores, Cárcano valuaba públicamente la herencia del autor de la Historia de Belgrano en tanto piedra fundante de una manera de escribir la historia argentina digna de prolongar. En ese sentido, Mitre oficiaba para Cárcano de faro indiscutido de una "tradición progresiva" al servicio de la república y la Junta de Historia y Numismática, una principalísima concreción "desinteresada" integrada por hombres de distintos rumbos del país que amaban la patria y entendían cómo servirla en concordancia, en la armonía del ya debatido consenso liberal.

\section{Profile}

Eduardo Escudero es Profesor y Licenciado en Historia (Facultad de Ciencias Humanas de la UNRC), Doctor en Historia (Facultad de Filosofía y Humanidades de la UNC, 2015) y Posdoctor en Ciencias Sociales (Facultad de Ciencias Sociales de la UNC, 2017). Ejerce la docencia por concurso en la Escuela de Historia, Facultad de Filosofía y Humanidades, UNC y en el Departamento de Historia, Facultad de Ciencias Humanas, UNRC. En los últimos años ha desarrollado estudios sobre la problemática de los vínculos entre Historiografía, Memoria y Política en la Argentina Contemporánea y sobre distintos nudos claves de la Historia de la Historiografía argentina

Eduardo Escudero is Professor and Bachelor in History (Human Sciences School of the UNRC), Doctor in History (Faculty of Philosophy and Humanities of the UNC, 2015) and Postdoctoral in Social Sciences (Faculty of Social Sciences of the UNC, 2017). He teaches by competition in the School of History, Faculty of Philosophy and Humanities, UNC and in the Department of History, Faculty of Human Sciences, UNRC. In recent years he has developed studies on the problematic of the links between Historiography, Memory and Politics in Contemporary Argentina and on different key knots of the History of Argentine Historiography 
Fecha de recepción: 30 de septiembre de 2017.

Fecha de aceptación: 2 de abril de 2018.

Publicación: 31 de diciembre de 2018.

Para citar este artículo: Eduardo A. Escudero, "Ramón J. Cárcano: ejercicio de la historiografía, liberalismo y diplomacia. Una aproximación”, Historiografías, 16 (juliodiciembre, 2018): pp. 76-97. 